12

\title{
Сажеобразование в процессе разложения хлорсодержащих углеводородов плазмотроном переменного тока
}

\author{
(C) Н.В. Образцов, Д.И. Субботин, А.В. Суров, В.Е. Попов, Е.О. Серба \\ Институт электрофизики и энергетики РАН, \\ 191186 Санкт-Петербург, Россия \\ e-mail: nikita.obrazcov@mail.ru
}

Поступило в Редакцию 28 июля 2017 г.

В окончательной редакции 11 ноября 2017 r.

Принято к публикации 18 июня 2020 г.

Исследован процесс разложения хлорорганических соединений трехфазным плазмотроном переменного тока с вихревой стабилизацией дуги. Плазмотрон имел две зоны ввода плазмообразующих сред: приэлектродную и зону горения дуги. В приэлектродную зону подавался защитный газ, а зону горения дуги водяной пар, метан и пары хлорорганических соединений. Образующиеся продукты проанализированы методом масс-спектрометрии, XRD, сканирующей электронной микроскопии, ИК-спектроскопии. В опыте с хлорбензолом и тетрахлорметаном в газообразной и жидкой фракциях удалось обнаружить только одно хлорсодержащее соединение - HCl. Однако в опыте с хлорбензолом выход сажи составил $0.98 \%$ масс от сырья, а содержание хлора в саже - 1.61\%. Данные ИК-спектров подтверждают наличие связи $\mathrm{Cl}-\mathrm{O}$ и $\mathrm{Cl}-\mathrm{C}$.

Ключевые слова: плазмотрон, хлорорганические соединения, сажа, хлороводород, электрическая дуга.

DOI: 10.21883/JTF.2020.12.50136.2459

\section{Введение}

Хлорсодержащие отходы представляют собой одну из основных экологических проблем, поскольку при захоронении они могут просачиваться в сточные воды, а их сжигание приводит к образованию диоксинов, новых соединений, которые еще более опасны. Основными возможными методами переработки отходов являются прямое сжигание [1,2], каталитическое восстановление [3] и плазменные методы $[4,5]$. В настоящее время плазмохимические методы могут быть использованы для широкого спектра процессов плазменно-химического разложения: переработки токсичных отходов [4], газификации бытовых твердых отходов [6], плазменного риформинга углеводородов [7]. Разложение органического материала основано на полном перемешивании и высокой скорости реакции между компонентами сырья. Для надежного разложения сложных органических соединений необходимо обеспечить температуру на выходе из реакционной зоны не менее $1250^{\circ} \mathrm{C}$ и время пребывания компонентов в высокотемпературной зоне до $2 \mathrm{~s}$. В случае эффективного охлаждения продуктов реакции многоатомные соединения, разрушенные в плазме, обратно не синтезируются. Использование пара в качестве плазмообразующего газа вместо воздуха имеет ряд преимуществ. Во-первых, исключается участие азота в реакции и соответственно отсутствует риск образования токсичных соединений азота. Во-вторых, объем отработанных газов в 2-3 раза меньше, чем в воздушной плазме, что снижает стоимость очистки газа $[8,9]$. Если исходное соединение не содержит достаточно водорода для связывания хлора, необходимо также ввести насыщенные углеводороды (метан), образующие водород с паром в высокотемпературной зоне. Современные конструкции плазмотронов могут работать на плазмообразующих смесях, содержащих метан и пар [10,11]. Это дает дополнительное преимушество для плазменных методов по сравнению с другими типами обработки хлорорганических соединений. Однако в процессе разложения хлорорганических соединений в плазме сажа может образоваться из-за недостатка водяного пара $[12,13]$. Эта сажа может включать сложные хлорорганические соединения с высокой термической и биологической стабильностью.

\section{1. Термодинамический расчет}

В программе ChemicalWorkBench 3.5 была проведена термодинамическая оценка, и в диапазоне температур от 1000 до $4000 \mathrm{~K}$ был получен состав компонентов плазмы. В программе для оценки использовался термодинамический равновесный реактор типа РТ (постоянное давление и температура). Расчет проводился для двух потоков, смешивающихся в идеализированном адиабатическом реакторе:

1. Поток хлорорганического соединения $\left(\mathrm{CCl}_{4}\right.$ или $\left.\mathrm{C}_{6} \mathrm{H}_{5} \mathrm{Cl}\right)$.

2. Поток плазмообразующей смеси $\left(\mathrm{H}_{2} \mathrm{O}, \mathrm{CO}_{2}, \mathrm{CH}_{4}\right)$.

В качестве данных для расчета массовые расходы плазмообразующих сред были взяты из экспериментов, которые соответствуют устойчивой работе плазмотрона [14]. Расчетные данные приведены в табл. 1. 
Таблица 1. Параметры расчета

\begin{tabular}{|c|c|c|c|c|}
\hline \multicolumn{3}{|c|}{ Разложение $\mathrm{CCl}_{4}$ (рис. 1) } & \multicolumn{2}{|c|}{$\begin{array}{c}\text { Параметры реактора } P=1 \mathrm{~atm} . \\
T=(1000-4000) \mathrm{K}\end{array}$} \\
\hline Поток & Концентрация, \% wt. & Вещество & Расход, kg/h & $T, \mathrm{~K}$ \\
\hline 1 & 100 & $\mathrm{CCl}_{4}$ & 8.784 & \multirow[t]{3}{*}{373} \\
\hline \multirow[t]{2}{*}{2} & $\begin{array}{l}41.37 \\
41.37\end{array}$ & $\begin{array}{l}\mathrm{H}_{2} \mathrm{O} \\
\mathrm{CO}_{2}\end{array}$ & \multirow[t]{2}{*}{25.236} & \\
\hline & 17.26 & $\mathrm{CH}_{4}$ & & \\
\hline
\end{tabular}

\begin{tabular}{c|c|c|c|}
\hline 1 & 100 & $\mathrm{C}_{6} \mathrm{H}_{5} \mathrm{Cl}$ & 14.4 \\
\hline \multirow{2}{*}{2} & 47.54 & $\mathrm{H}_{2} \mathrm{O}$ & 21.96 \\
\cline { 2 - 4 } & 47.54 & $\mathrm{CO}_{2}$ & \\
\cline { 2 - 4 } & 4.92 & $\mathrm{CH}_{4}$ &
\end{tabular}

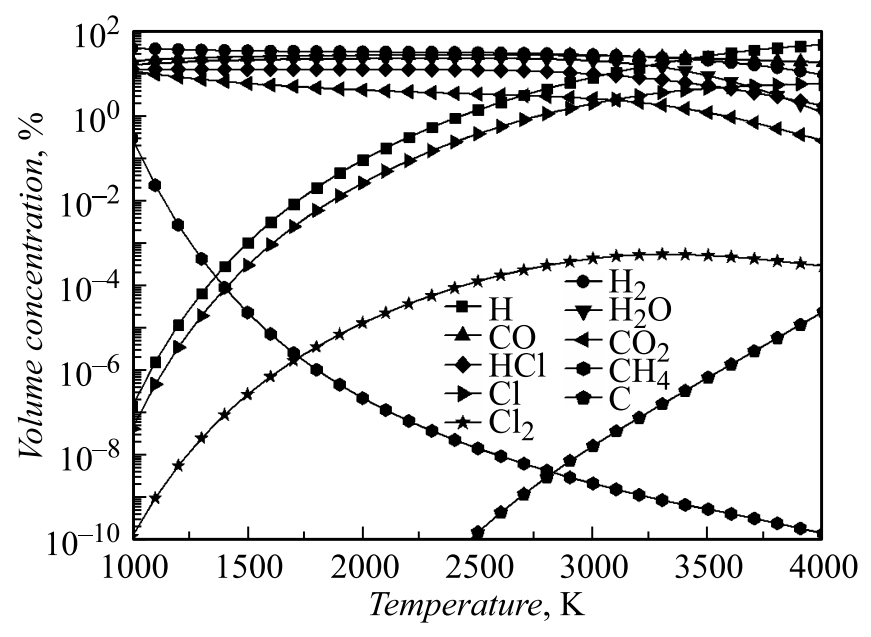

Рис. 1. Зависимость объемной концентрации веществ в плазме от температуры при разложении $\mathrm{CCl}_{4}$.

Как видно из рис. 1 и 2, с увеличением температуры содержание метана и водяного пара снижается, что свидетельствует о повышении эффективности переработки. Исходные хлорорганические соединения не показаны, так как в присутствии водяного пара они термодинамически неустойчивы в указанном диапазоне температур. При этом основным хлорсодержащим продуктом реакции является хлороводород. Он образуется в результате реакции атомов хлора с водородом, полученной при риформинге метана водяным паром.

Кроме того, видно, что при той же температуре степень превращения метана для реакции с хлорбензолом меньше, чем для тетрахлорметана. Из этого можно сделать вывод, что хлорбензол более устойчив по сравнению с тетрахлорметаном, и его разложение

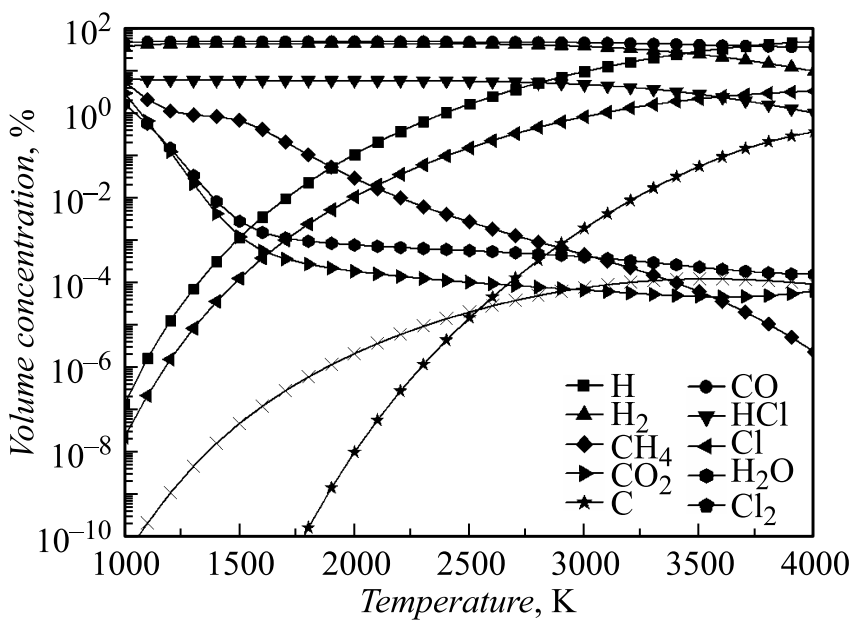

Рис. 2. Зависимость объемной концентрации веществ в плазме от температуры при разложении $\mathrm{C}_{6} \mathrm{H}_{5} \mathrm{Cl}$.

потребует больше энергии и большего расхода водяного пара.

\section{2. Экспериментальное исследование}

Возможность использования плазмотрона переменного тока рассматривалась для широкого круга опасных хлорорганических веществ [15]. В качестве модельных веществ были выбраны тетрахлорметан $\mathrm{CCl}_{4}$ и хлорбензол $\mathrm{C}_{6} \mathrm{H}_{5} \mathrm{Cl}$. Экспериментальное исследование по разложению тетрахлорметана и хлорбензола проводится на лабораторной установке, показанной на рис. 3. В качестве плазменного генератора используется высоковольтный трехфазный плазмотрон переменного тока [14], который также использовался для плазменного риформинга метана [16]. Плазмотрон представляет собой 


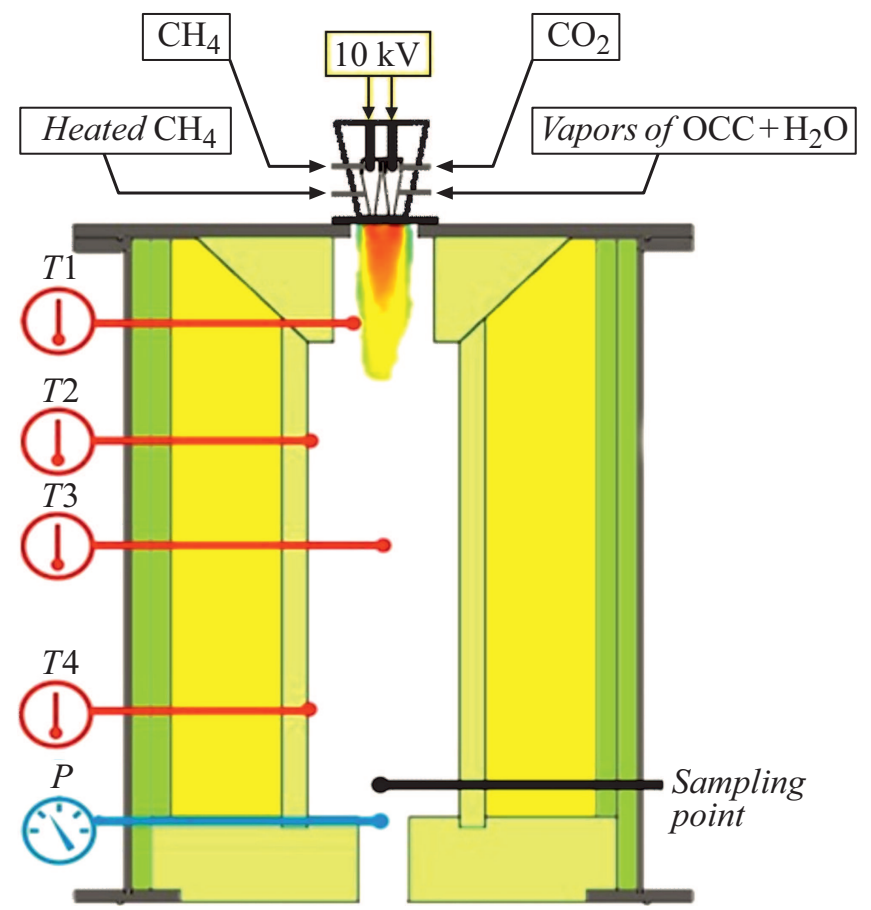

Рис. 3. Экспериментальная установка: $T-$ термопара, $P-$ датчик давления, ОСС - хлорорганические соединения.

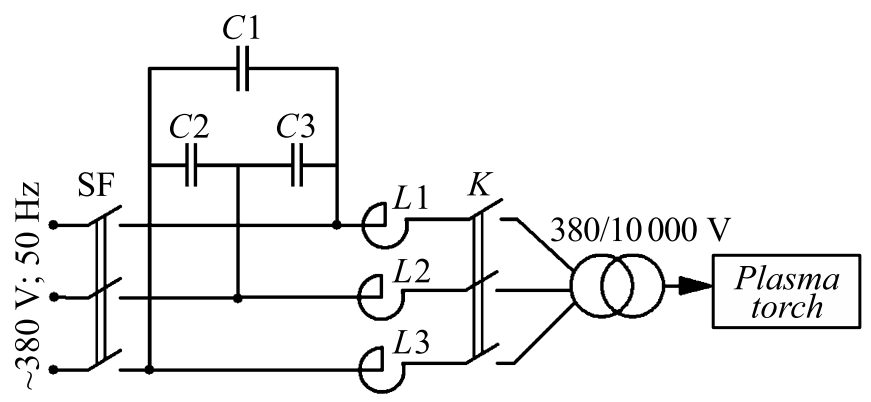

Рис. 4. Источник питания: $\mathrm{SF}-$ автоматический выключатель; $C_{1}, C_{2}, C_{3}-$ компенсатор реактивной мощности, $L_{1}, L_{2}, L_{3}$ - токоограничивающие реакторы, $K-$ контактор, Plasma torch - плазмотрон.

устройство с медными стержневыми водоохлаждаемыми электродами в трех отдельных цилиндрических электроразрядных каналах. В каждом канале организованы две области тангенциальной подачи плазмообразующих веществ. В области электродов подается защитный газ $\mathrm{CO}_{2}$, а смесь пара, паров органического соединения и метана поступает в разрядные каналы за электродами. Тангенциальный вход плазмообразующей среды обеспечивает осевую стабилизацию дугового разряда. Зажигание дуг во время запуска плазмотрона происходит за счет независимого пробоя в зазорах между электродами и стенками разрядных каналов приложением высокого напряжения холостого хода источника питания (рис. 4).
Тетрахлорметан и хлорбензол имеют невысокие температуры кипения - 77 и $131^{\circ} \mathrm{C}$ соответственно. Это позволяет нагревать хлорорганические соединения в испарителе-пароперегревателе до температуры испарения и затем подавать его в плазмотрон в газообразном состоянии. В плазмотроне пары органического вещества смешиваются с нагретым метаном, водяным паром и двуокисью углерода. Поток плазмы этой смеси поступает в футерованный реактор, где происходит основной процесс разрушения хлорорганических соединений. Реактор оснащен датчиками температуры $T$ и давления $P$. Отбор проб реакционных газов для анализа состава осуществляется из нижней части реактора. Затем образец охлаждается, и из него удаляется конденсат. Конденсат анализируют на содержание хлористого водорода, и охлажденный газообразный продуктовый газ направляют для непрерывного анализа его основного состава с использованием массспектрометра и ИК-фурье-спектрометра. Сажу собирают на кварцевом микроволоконном фильтре, чтобы определить его количество гравиметрическим методом (ISO 9096). Состав и свойства сажи определяются c помощью сканирующей электронной микроскопии, рентгеновской флуоресцентной спектроскопии, рентгеноструктурного анализа и FTIR-спектроскопии (Fourier Transform Infrared Spectroscopy). Расходы плазмообразующих сред определяются из следующих стехиометрических уравнений:

Эксперимент с $\mathrm{C}_{6} \mathrm{H}_{5} \mathrm{Cl}$ :

$$
\begin{gathered}
\mathrm{C}_{6} \mathrm{H}_{5} \mathrm{Cl}+6 \mathrm{H}_{2} \mathrm{O}=6 \mathrm{CO}+8 \mathrm{H}_{2}+\mathrm{HCl}, \\
\mathrm{C}_{6} \mathrm{H}_{5} \mathrm{Cl}+6 \mathrm{CO}_{2}=12 \mathrm{CO}+2 \mathrm{H}_{2}+\mathrm{HCl}, \\
\mathrm{CH}_{4}+\mathrm{H}_{2} \mathrm{O}=\mathrm{CO}+3 \mathrm{H}_{2}, \\
\mathrm{CH}_{4}+\mathrm{CO}_{2}=2 \mathrm{CO}+2 \mathrm{H}_{2}, \\
\mathrm{CH}_{4}-0.3 \mathrm{~g} / \mathrm{s}, \quad \mathrm{H}_{2} \mathrm{O}-2.9 \mathrm{~g} / \mathrm{s}, \\
\mathrm{CO}_{2}-2.9 \mathrm{~g} / \mathrm{s}, \quad \mathrm{C}_{6} \mathrm{H}_{5} \mathrm{Cl}_{4}-2.44 \mathrm{~g} / \mathrm{s} .
\end{gathered}
$$

Эксперимент с $\mathrm{CCl}_{4}$ :

$$
\begin{aligned}
& \mathrm{CCl}_{4}+1.049 \mathrm{H}_{2} \mathrm{O}+0.427 \mathrm{CO}_{2}+0.476 \mathrm{CH}_{4} \\
&=1.903 \mathrm{CO}+4 \mathrm{HCl} \\
& \mathrm{CH}_{4}-1.21 \mathrm{~g} / \mathrm{s}, \quad \mathrm{H}_{2} \mathrm{O}-2.9 \mathrm{~g} / \mathrm{s} \\
& \mathrm{CO}_{2}-2.9 \mathrm{~g} / \mathrm{s}, \quad \mathrm{CCl}_{4}-2.44 \mathrm{~g} / \mathrm{s}
\end{aligned}
$$

\section{3. Результаты}

В табл. 2 приведены результаты экспериментального исследования: объемная концентрация осушенного продуктового газа, измеренная масс-спектрометром, мощность плазмотрона, средняя температура в реакторе во время эксперимента и образование сажи.

Сравнение экспериментальных и расчетных параметров (табл. 3) показало, что хлорбензол практически 
Таблица 2. Результаты

\begin{tabular}{c|c|c|c|c|c|c|c|c}
\hline Эксперимент & $\mathrm{CH}_{4}$ & $\mathrm{H}_{2}$ & $\mathrm{CO}_{2}$ & $\mathrm{CO}$ & $\mathrm{HCl}$ & Сажа & Сила, $\mathrm{kW}$ & $T, \mathrm{~K}$ \\
\hline $\mathrm{CCl}_{4}$ & $1.84 \%$ & $32.44 \%$ & $33.62 \%$ & $12.97 \%$ & $19.13 \%$ & - & 116.6 & 1400 \\
\hline $\mathrm{C} 6 \mathrm{H}_{5} \mathrm{Cl}$ & $0.04 \%$ & $45.05 \%$ & $3.13 \%$ & $45.51 \%$ & $6.27 \%$ & + & 106 & 1250
\end{tabular}

Таблица 3. Сравнение экспериментальных данных с расчетными для $\mathrm{C}_{6} \mathrm{H}_{5} \mathrm{Cl} T=1250$

\begin{tabular}{c|c|c|c|c|c}
\hline$T=1250 \mathrm{~K}$ & $\mathrm{CH}_{4}$ & $\mathrm{H}_{2}$ & $\mathrm{CO}_{2}$ & $\mathrm{CO}$ & $\mathrm{HCl}$ \\
\hline Расчет & $0.9 \%$ & $43.5 \%$ & $0.05 \%$ & $49.3 \%$ & $6 \%$ \\
\hline Эксперимент & $0.04 \%$ & $45.05 \%$ & $3.13 \%$ & $45.51 \%$ & $6.27 \%$
\end{tabular}

Таблица 4. Сравнение экспериментальных данных с расчетными для $\mathrm{CCl}_{4}$

\begin{tabular}{c|c|c|c|c|c}
\hline$T=1400 \mathrm{~K}$ & $\mathrm{CH}_{4}$ & $\mathrm{H}_{2}$ & $\mathrm{CO}_{2}$ & $\mathrm{CO}$ & $\mathrm{HCl}$ \\
\hline Расчет & $0 \%$ & $44.15 \%$ & $7.53 \%$ & $32 . \%$ & $16.19 \%$ \\
\hline Эксперимент & $1.84 \%$ & $32.44 \%$ & $33.62 \%$ & $12.97 \%$ & $19.13 \%$
\end{tabular}

полностью превратился в хлороводород, что связано с высокой температурой процесса и наличием избытка водяного пара. Однако часть хлорбензола превратилась с сажу, обнаруженную на кварцевом фильтре.

Результаты эксперимента с тетрахлорметаном сильно отличаются от расчетных (табл. 4), что связано с большим избытком водяного пара, который реагирует с монооксидом углерода при более низких температурах:

$$
\mathrm{CO}+\mathrm{H}_{2} \mathrm{O}=\mathrm{H}_{2}+\mathrm{CO} \text {. }
$$

При этом в эксперименте с тетрахлорметаном сажи не обнаружено, что говорит о высокой степени превращения тетрахлорметана. Указанные особенности сажеобразования закономерны, так как хлорбензол может разлагаться до сажи в области относительно низких температур при контакте с плазмой водяного пара и углекислого газа. Кроме того, содержание сажи будет тем больше, чем меньше избыток водяного пара и чем сложнее вещество будет подвергаться разложению.

Из-за высокого расхода в эксперименте с хлорбензолом активно образуется сажа; выход сажи составляет 0.98 mass.\% от исходного сырья. Сажа содержит продукты эрозии электродов и корпуса плазмотрона $(\mathrm{Fe}, \mathrm{Ni}, \mathrm{Cr}$ и $\mathrm{Cu}$ ). Состав сажи выглядит следующим образом (без материала фильтра): С -68.87 wt.\%, O -15.53 wt.\%, $\mathrm{Cl}-2.08$ wt.\%, $\mathrm{Cr}-0.94$ wt.\%, $\mathrm{Mn}-0.56$ wt.\%, Fe 7.68 wt. $\%, \mathrm{Ni}-0.48$ wt $\%, \mathrm{Cu}-3.87$ wt.\%. Микрофотография образца с материалом фильтра представлена на

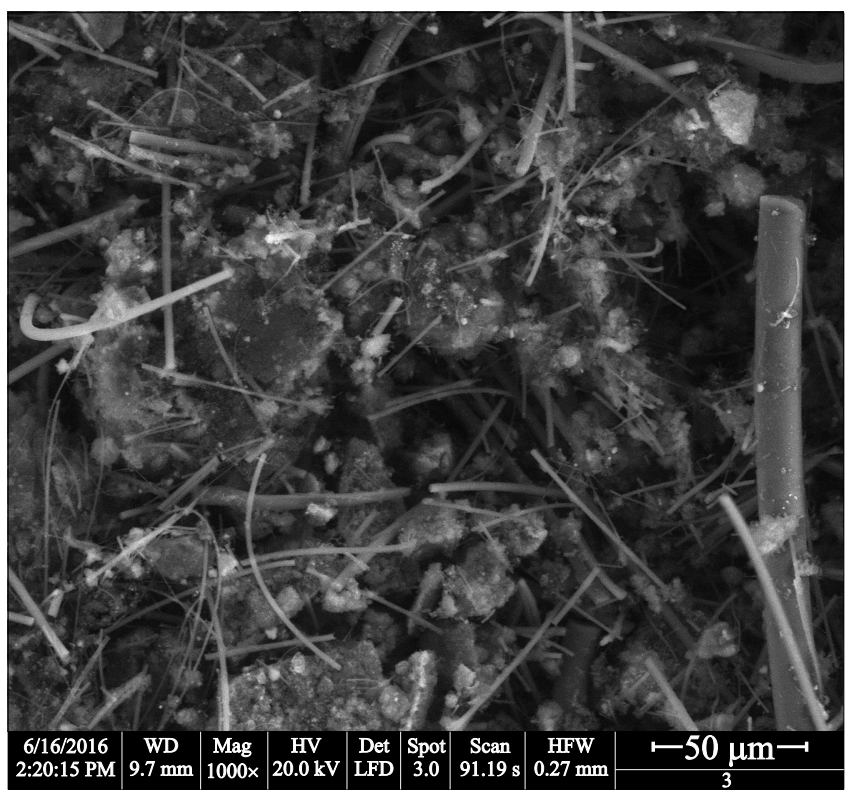

Рис. 5. Микрофотография сажи с материалом фильтра.

рис. 5, на котором видны частицы сажи сложной формы и материал фильтра - длинные трубки.

Полученная проба была исследована с помощью ИКфурье-спектрометра (рис. 6). На спектре видны колебания связей $\mathrm{Cl}-\mathrm{O}, \mathrm{C}-\mathrm{Cl}$, подтверждающие присутствие хлора, химически связанного с углеродом сажи.

Из этого становится ясно, что процесс разложения хлорорганических соединений под действием плазмы водяного пара, углекислого газа и метана протекает в двух направлениях: гидрирование-газификация органических молекул с образованием водорода, моноокосида углерода и хлороводорода; реакции уплотнения с образованием более сложных соединений, содержащих хлор. При этом алифитические соединения, такие как тетрахлорметан, в большей степени разлагаются с образованием хлороводорода, водорода и монооксида углерода, чем ароматические вещества. Ароматическое кольцо хлорбензола склонно к образованию дополнительных связей с соседними молекулами, что приводит к образованию сажи. Исходных хлорбензол содержит 31.6 mass.\% хлора, в образующейся саже его 2.08 mass.\%, что говорит о вытеснении атомов хлора из исходных молекул в процессе конденсации. Эти обстоятельства позволяют предположить, что увеличение времени пребывания и избытка водяного пара приведет к снижению выхода 


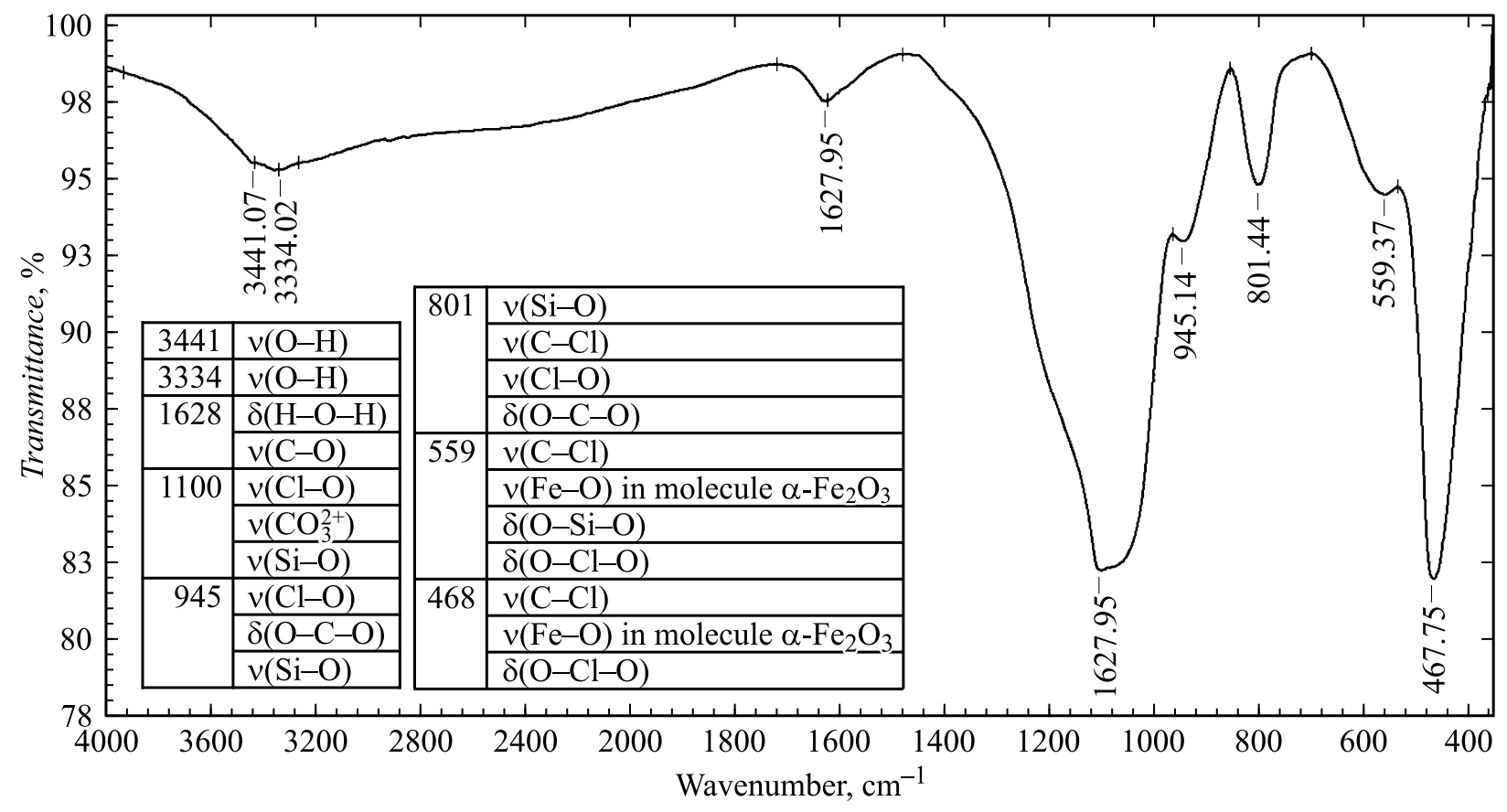

Рис. 6. ИК-спектр сажи с материалом фильтра.

сажи и содержанию в ней хлора. Повышать температуру в плазмохимическом реакторе не целесообразно, поскольку это приведет к снижению срока службы футеровки реактора и резкому росту энергозатрат.

\section{Заключение}

Работа показывает, что более высокое содержание углерода в $\mathrm{C}_{6} \mathrm{H}_{5} \mathrm{Cl}$, чем в $\mathrm{CCl}_{4}$, и более сложная структура молекул приводит к образованию сажи, содержащей хлор. Сокращение расхода метана позволяет уменьшить образование сажи, но в то же время мощность плазмотрона незначительно уменьшается. Дополнительное введение пара уменьшит образование сажи или полностью предотвратит ее образование, но это приведет к увеличению затрат электроэнергии. Учитывая выполненные эксперименты, можно сказать, что ароматические углеводороды (например, $\mathrm{C}_{6} \mathrm{H}_{5} \mathrm{Cl}$ ) активно превращаются в хлорсодержащую сажу, которая может быть использована для получения углеродного покрытия, активного по отношению к тяжелым металлам.

\section{Финансирование работы}

Работы выполнена при поддержке Министерства образования и науки Российской федерации в рамках государственного задания № 0057-2019-0002.

\section{Конфликт интересов}

Авторы заявляют, что у них нет конфликта интересов.

\section{Список литературы}

[1] D.R. McIlveen-Wright, F. Pinto, L. Armesto, M.A. Caballero, M.P. Aznard, A. Cabanillas, Y. Huang, C. Franco, I. Gulyurtlu, J.T. McMullan. Fuel Processing Technology, 87 (9), 793 (2006).

[2] A.A. Khan, W. de Jong, P.J. Jansens, H. Spliethoff. Fuel Processing Technology, 90 (1), 21 (2009).

[3] D.G. Olson, K. Tsuji, I. Shiraishi. Fuel Processing Technology, 65-66, 393 (2000).

[4] Xinchao Pan, Jianhua Yan, Zhengmiao Xie. J. Environmental Sciences, 25 (7), 1362 (2013).

[5] Marco Schiavon, Marco Scapinello, Paolo Tosi, Marco Ragazzi, Vincenzo Torretta, Elena Cristina Rada. J. Cleaner Production, 104, 211 (2015).

[6] S. Evangelisti, C. Tagliaferri, R. Clift, P. Lettieri, R. Taylor, C. Chapman. Waste Management, 43, P. 485 (2015).

[7] Dariusz Czylkowski, Bartosz Hrycak, Mariusz Jasiński, Mirosław Dors, Jerzy Mizeraczyk. Energy, 113 (C), 2016, 653 (2016).

[8] Sang Jun Yoon, Jae-Goo Lee. Inter. J. Hydrogen Energy, 37 (22), 17093 (2012).

[9] A.S. Lerner, A.N. Bratsev, V.E. Popov, V.A. Kuznetsov, A.A. Ufimtsev, S.V. Shengel, D.I. Subbotin. Glass Physics and Chemistry, 38 (6), 511 (2012).

[10] Dong Hun Shin, Yong Cheol Hong, Sang Ju Lee, Ye Jin Kim, Chang Hyun Cho, Suk Hwal Ma, Se Min Chun, Bong Ju Lee, Han Sup Uhm. Surface and Coatings Technology, 228 (Supplement 1), S520 (2013).

[11] Andrius Tamošiūnas, Pranas Valatkevičius, Viktorija Grigaitienė, Vitas Valinčius, Nerijus Striūgas. J. Cleaner Production, 130, 187 (2016).

[12] Tomasz Jedrzejczyk, Zbigniew Kołacński, Dariusz Koza, Grzegorz Raniszewski, Łukasz Szymański, Sławomir Wiak. OpenChem., 13, 156 (2015). 
[13] P. Fazekas, E. Bodis, A.M. Keszler, Z. Czegeny, S. Klebert, Z. Karoly, J. Szepvolgyi. Plasma Chem. Plasma Proc., 33, 765 (2013).

[14] Ph.G. Rutberg, Gh.V. Nakonechny, A.V. Pavlov, S.D. Popov, E.O. Serba, A.V. Surov. J. Phys. D: Appl. Phys., 48, 245204 (2015).

[15] Н.В. Образцов, В.Е. Попов, Д.И. Субботин. Неделя науки СПбПУ. Материалы научного борума с международным участием. (Институт энергетики и транспортных систем, СПб, 2015). С. 144.

[16] Ph.G. Rutberg, V.E. Kuznetsov, V.E. Popov, S.D. Popov, A.V. Surov, D.I. Subbotin, A.N. Bratsev. Appl. Energy, 148, 159 (2015). 